\title{
Pengaruh Teknik Treasure Hunt Game Berbasis Model Think Pair Share Terhadap Pengaruh Hasil Belajar Matematika Siswa Kelas III
}

\author{
Riza Yunita Cahyani ${ }^{1}$, Dewi Triyanasari ${ }^{2}$, Pinkan Amita Tri ${ }^{3}$ \\ 1,2,3Program Studi Pendidikan Guru Sekolah Dasar, Universitas PGRI Madiun, rizayunita325@gmail.com
}

\begin{abstract}
ABSTRAK
Penelitian ini bertujuan untuk mengetahui adanya Pengaruh Teknik Treasure Hunt Game berbasis Model Think Pair Share Terhadap Hasil Belajar Matematika Siwa SD Kelas III. Penelitian ini merupakan penelirian kuantitatif dengan jenis OneGroup Pretest-Posttest. Pengujian hipotetis menggunakan t-test, diperoleh data hasil $t_{\text {hitung }}=20,30$ dengan $t_{\text {tabel }}=2,101$. Dengan demikian karena $t_{\text {hitung }}>t_{\text {tabel }}$ $(20,30>2,101)$ maka Ho ditolak dan Ha diterima
\end{abstract}

Kata Kunci: Treasure Hunt Game, Think Pair Share, Soal Cerita.

\begin{abstract}
This study aims to determine the effect of the Treasure Hunt Game Technique based on Think Pair Share Model on Class III Mathematics Shiva Learning Outcomes. This research is quantitative research with the type of Pretest-Posttest One-Group. Hypothetical testing using a t-test, obtained data results of $t_{\text {count }}=20.30$ with $t$ table $=2.101$. Thus because $t_{\text {count }}>t_{\text {table }}(20.30>2.101)$ then Ho is rejected and $\mathrm{Ha}$ is accepted.
\end{abstract}

Kata Kunci: Treasure Hunt Game, Think Pair Share, Story Problem.

\section{Pendahuluan}

Didi Haryono [1] Menyatakan bahwa matematika ialah salah satu ilmu pengetahuan yang memiliki sifat pasti. Asal kata matematika ialah dari Bahasa Latin yaitu Machematica. Matematika yang merupakan istilah dari Yunani memiliki pengertian relating to learning atau pengkajian, pembelajaran, ilmu ataupun pengetahuan. Jadi berdasarkan asal-usul katanya matematika berarti pengetahuan yang diperoleh dari hasil proses dalam belajar, sehingga matematika dikatakan suatu pengetahuan. Sedangkan Aristoteles memiliki pendapat bahwa ia melihat matematika sebagai salah satu dari tiga dasar yang membagi ilmu pengetahuan menjadi ilmu fisik, matematika, dan teologi. Matematika memiliki dasar pada kejadian yang pernah dialami, yaitu pengetahuan yang didapatkan dari eksperimen, observasi dan abstraksi.

Mata pelajaran matematika merupakan pelajaran penting yang sangat diperlukan untuk diajarkan kepada siswa Sekolah Dasar (SD) dengan mendapatkan bekal pelajaran tersebut siswa sudah mendapatkan bekal untuk berfikir logis, analitis, kristis, dan juga 
kreatif. Kemampuan tersebut sangat dibutuhkan oleh siswa untuk memperoleh dan mengelola informasi yang digunakan untuk bertahan hidup dengan keadaan atau kondisi yang berubah-ubah.

Pada saat ini masih banyak sekolah terutama guru yang menggunakan teknik ataupun model pembelajaran yang monoton, yang mengakibatkan siswa bosan, tidak focus dan lebih asyik bermain dengan temannya saat pelajaran berlangsung. Keadaan tersebut berdampak pada hasil belajar siswa yang berada dibawah standar kelulusan. Sehubungan dengan keaadaan tersebut di atas, akan digunakan teknik pembelajaran Treasure Hunt Game yang diharapkan dapat meningkatkan hasil belajar siswa.

Menurut Oxford Advanced Learner's Pocket Dictionary [2] Treasure adalah koleksi perak perhiasan emas atau lainnya. Dan kata Hunt yang berarti berburu, yang dimaksutkan untuk mencari seseorang atau sesuatu. Jadi Treasure Hunt Game dapat didefinikan sebagai permainan yang dimainkan oleh pemain untuk mencari dan mengkoleksi sesuatu seperti emas, perak, perhiasan atau yang lainnya. Dalam permainan ini menuntut siswa untuk aktif mencari harta atau yang dimaksutkan dalam pelajaran ini adalah sebuah jawaban melalui petunjuk-petunjuk yang telah disediakan. Permainan ini dapat dimainkan dimana saja dan oleh siapa saja, jadi jika diterapkan dalam proses pembelajaran dapat dimainkan diluar kelas dan membuat siswa tidak bosan dengan keadaan pembelajaran di dalam ruangan. Cara atau prosedur pelaksanaan Treasure Hunt Game adalah 1) Gurummemberikan penjelasan tentangjaturan permainan, 2) Masingmasingnkelompok mengambilwkertas yang ada di kotak yang sudah disediakan, 3) Melakukan kegiatan sesuaiydengan petunjuk yang ada dalam kertas, 4) Kembali ke tempatmsemula denganwmembawa benda-benda yang sudahqdiambil, 5) Melaporkanhhasilwpencarian dan ditulishdalam tabel.

Penggunaan teknik ini dipadukan dengan model pembelajaran Think Pair Share karena didasarkan pada teori Sumarmo dalam Tandilling [3] mengatakan jika pembelajaran matematika diterapkan agar mendorongnsiswa dapat berfikir secaramkreatif dannberfikir tingkat tinggiwdapat dilakukan melaluipbelajar dalamekelompok kecil. Sedangkan model ini merupakan model pembelajaran yang mengacu pada pembentukan kelompok-kelompok kecil dan kemudian bekerja sama dan saling membantu. Dalam model Think Pair Share ini ada tiga fase yaitu : 1) Berfikir, pada fase ini guru memancing siswa dengan sebuah pertanyaan, hanya dengan waktu beberapa menit saja siswa harus berfikir tentang pertanyaan yang telah diberikan, 2) Berpasangan, menggunakan pasangan atau berpasangan dengan teman sebangku untuk membicarakan jawaban dari pertanyaan yang telah diberikan. Dengan mengungkapkan pendapat secara langsung ataupun tertulis dan mengidentifikasi jawaban terbaik menurut mereka, 3) Berbagi, setelah siswa berdiskusi dengan pasangannya beberapa saat, guru memanggil satu kelompok atau sepasang siswa untuk mengkomunikasikan jawabannya dengan pasangan lain.

Penelitian ini fokus pada materi yang terkait dengan soal cerita. Soal cerita adalah soal yang disajikan dalam bentuk lisan ataupun tulisan, soal cerita yang berbentuk tulisan berupa kalimat yang mengilustrasikan kegiatan dalam kehidupan sehari-hari [4]. Ratarata kemampuan siswa dalam mengerjakan soal cerita masih di bawah standar kelulusan yang ditetapkan. Memahamimmakna konsep dan ungkapan dalam sebuah soal cerita sertammengubahnya ke dalam simbol-simbol dan relasi matematikambukanlah sesuatu yang dianggap mudah bagi sebagian siswa. Dalam pembelajaran, siswa biasanya diberikan soal atau masalah soal cerita setelah konsep matematika diajarkan ke siswa. Dengan demikian, siswa jarang mendapatkan kesempatan untuk memecahkan masalah matematika yang mengarahkan siswa untuk melakukan proses matematika. Tujuan dari penelitian ini adalah untuk mengetahui adanya pengaruh Teknik Treasure Hunt Game 
berbasis Model Think Pair Share terhadap Hasil Belajar Matematika siswa kelas III SDN 03 Madiun Lor.

\section{Metode Penelitian}

Penelitian ini dilaksanakan dengan menggunakan metode eksperimen PreExperimental Designs dengan jenis One-Group Pretest-Postest. Sugiyono [5] mengemukakan bahwa "desain ini terdapat pretest, dengan demikian hasil perlakuan dapat diketahui lebih akurat, karena dapat membandingkan dengan keadaanmsebelum diberi perlakuan. Penelitian ini bertujuan untuk mengetahui perbandingan sebelum dan setelah diberikan perlakuan terhadap independen. Desain ini dapat digambarkan sebagai berikut:

TABEL 1 One-Group Pretest-Posttest Design

\section{$\mathbf{O}_{1} \mathrm{X} \mathrm{O}_{2}$}

Keterangan:

$\mathrm{O} 1$ : nilai pre-test (sebelum diberimdiklat)

$\mathrm{O} 2$ : nilai post-test (setelah diberi diklat)

Populasi yang digunakan dalam penelitian ini adalah siswa kelas IIIA SDN 03 Madiun Lor. Pengambilan sampel menggunakan nonprobability Sampling dengan teknik Sampling Jenuh yang merupakan teknik dengan semua anggota populasi merupakan sampel dalam penelitian.

Teknik pengumpulan data yang digunakan dalam penelitian ini menggunakan metode tes. Metode tes tersebut digunakan untuk memperoleh data adanya perubahan hasil belajar siswa melalui nilai rata-rata pretest dan posttest. Menurut Arikunto [6] tes merupakan serentetan pertanyaan atau latihan serta alat lain yang digunakan untuk mengukur keterampilan, pengetahuan inteligensi, kemampuanwatau bakat yang dimiliki oleh individu atau kelompok. Data yang dikumpulkan adalah data nilai siswa kelas III SDN Madiun Lor.

Instrumen penelitian untuk mengeksplorasi hasil belajar siswa adalah dengan menggunakan tes berupa uraian yang berbentuk soal cerita. Soal tes sebelum digunakan untuk mengambil data penelitian, diuji cobakan terlebih dahulu agar mengetahui kualitas soal yang digunakan. Kelayakan instrumen penelitian ini diukur dengan menggunakan uji validitas dan uji reliabilitas.

\section{Hasil dan Pembahasan}

Data ini adalah data sebelum peserta didik diberikan perlakuan Teknik Treasure Hunt Game atau disebut dengan data Pre-Test, yang merupakan data awal. Berikut ini tabel distribusi data nilai hasil belajar peserta didik sebelum mendapat perlakuan Teknik Treasure Hunt Game: 
TABEL 1 Distribusi Data Nilai Sebelum Diberikan Perlakuan

\begin{tabular}{lrrr}
\hline \multicolumn{1}{l}{ No. } & Interval Kelas & Jumlah & Presentase $\%$ \\
\hline 1 & $30-34$ & 9 & $27.3 \%$ \\
\hline 2 & $35-39$ & 0 & $0.0 \%$ \\
\hline 3 & $40-44$ & 11 & $33.3 \%$ \\
\hline 4 & $45-59$ & 10 & $30.3 \%$ \\
\hline 5 & $60-64$ & 3 & $9.1 \%$ \\
\hline Jumlah & 33 & $100.0 \%$ \\
\hline Mean (Rata-rata) & & 14.12 \\
\hline Median & & 40 \\
\hline Modus & & 40 \\
\hline Nilai Tertinggi & & 60 \\
\hline Nilai Terendah & & 30 \\
\hline Standar Deviasi & & 9.6 \\
\hline
\end{tabular}

Dari data yang telah didapatkan dan diolah diketahui persentase ketuntasan peserta didik. Data tabel di bawah diketahui 3 peserta didik memenuhi kriteria tuntas, sedangkan 30 peserta didik tidak tuntas.

TABEL 3 Persentase Ketuntasan Hasil Belajar Pemahaman Peserta Didik Kelas III SDN 03 Madiun Lor

\begin{tabular}{|c|c|c|c|c|}
\hline No. & KKM & Jumlah & Presentase & Keterangan \\
\hline 1 & $>60$ & 3 & $9.09 \%$ & Tuntas \\
\hline \multirow[t]{2}{*}{2} & $<60$ & 30 & $90.91 \%$ & Tidak Tuntas \\
\hline & Jumlah & 33 & $100.00 \%$ & \\
\hline
\end{tabular}

Data berikut adalah data setelah peserta didik diberikan perlakuan teknik Treasure Hunt Game disebut juga data Post Test, merupakan nilai hasil belajar peserta didik setelah menerima perlakuan atau pembelajran dengan menggunakan teknik Treasure Hunt Game pada kelas IIIA SDN 03 Madiun Lor. Berdasarkan data yang telah diperoleh pada saat tes pemahaman soal cerita matematika kelas III SDN 03 Madiun Lor dengan jumlah peserta didik 33 .

TABEL 4 Distribusi Data Nilai Sesudah Diberikan Perlakuan

\begin{tabular}{llll}
\hline No. & Interval Kelas & Jumlah & Presentase \% \\
\hline 1 & $60-64$ & 2 & $6.06 \%$ \\
\hline 2 & $65-69$ & 0 & $0.00 \%$ \\
\hline 3 & $70-74$ & 12 & $36.36 \%$ \\
\hline 4 & $75-79$ & 0 & $0.00 \%$ \\
\hline 5 & $80-84$ & 15 & $45.45 \%$ \\
\hline 6 & $85-89$ & 0 & $0.00 \%$ \\
\hline 7 & $90-94$ & 4 & $12.12 \%$ \\
\hline Jumlah & 33 & $100.00 \%$ \\
\hline Mean (Rata-rata) & & 76.36 \\
\hline Median & & 80 \\
\hline Modus & 80 \\
\hline Nilai Tertinggi & 90 \\
\hline Nilai Terendah & 60 \\
\hline Standar Deviasi & 7.83 \\
\hline
\end{tabular}

Berdasarkan tabel di atas dapat diketahui nilai peserta didik setelah mendapatkan perlakuan yaitu: nilai tertinggi $=90$; dan nilai terendah $=60$, dengan rata-rata nilai 76,36 . 
Uji normalitas digunakan untuk mengetahui apakah sampel yang diambil berasal dari populasi yang berdistribusi normal atau tidak. Oleh karena itu data yang diambil harus diuji normalitas terlebih dahulu. Peneliti menggunakan uji normalitas dengan metode Liliefors.

TABEL 5 Hasil Uji Normalitas pada sampel

\begin{tabular}{llll}
\hline Tes & Lhitung & Ltabel & Keterangan \\
\hline Sebelum Perlakuan & 0,63 & 0,151 & Ho Diterima \\
\hline Setelah Perlakuan & 0,98 & 0,151 & Ho Diterima \\
\hline
\end{tabular}

Dari tabel di atas analisis uji normalitas pada sebelum menerima perlakuan di dapat L hitung $0,63<\mathrm{L}_{\text {tabel }} 0,151$ maka Ho diterima, sedangkan pada data setelah menerima perlakuan di dapat $\mathrm{L}_{\text {hitung }} 0,98<\mathrm{L}_{\text {tabel }} 0,151$ maka Ho diterima. Sehingga dapat disimpulkan bahwa data yang diperoleh dari kelas eksperimen berasal dari populasi yang terdistribusi normal.

Uji homogenitas adalah uji yang digunakan untuk mengetahui varian kedua sampel sama (homogen) atau tidak. Uji homogenitas dalam penelitian ini menggunakan uji F. Uji homogenitas dalam penelitian ini juga digunakan untuk menentukan rumus yang akan digunakan dalam uji statistik.

TABEL 6 Hasil Uji Homogenitas

\begin{tabular}{lllll}
\hline Variabel & Fhitung & Ftabel & Kriteria & Keterangan \\
\hline Hasil Belajar & 1,503 & 2,29 & $\mathrm{~F}_{\text {hitung }} \leq \mathrm{F}_{\text {tabel }}$ & Ha Diterima \\
Pemahaman Soal & & & & \\
Cerita Matematika & & & &
\end{tabular}

Berdasarkan tabel di atas dapat disimpulkan bahwa uji homogenitas menunjukkan bahwa Ha Diterima, sehingga sampel yang digunakan berasal dari populasi yang memiliki varian homogen.

Uji hipotesis digunakan untuk mengetahui perbandingan hasil belajar peserta didik pada Pre-Test ( sebelum mendapat perlakuan) dan pada saat Post-Test (setelah mendapat perlakuan). Untuk mengetahui apakah ada perbedaan atau pengaruh hasil belajar peserta didik antara pre-test dan post-test peneliti menggunakan uji-t.

Kriteria dari uji $t$ adalah sebagai berikut:

Jika $t_{\text {hitung }}<\mathrm{t}_{\text {tabel }}$ maka $\mathrm{H}_{\mathrm{o}}$ diterima

Jika $t_{\text {hitung }}>\mathrm{t}_{\text {tabel }}$ maka $\mathrm{H}_{\mathrm{a}}$ diterima

Keterangan:

1. $\mathrm{H}_{\mathrm{o}}$ diterima thitung $<\mathrm{t}_{\text {tabel }}$ maka Teknik Treasure Hunt Game berbasis model Think Pair and Share berpengaruh terhadap hasil belajar pemahaman matematika kelas III SDN 03 Madiun Lor

2. $\mathrm{H}_{\mathrm{a}}$ diterima $\mathrm{t}_{\text {hitung }}>\mathrm{t}_{\text {tabel }}$ maka maka Treasure Hunt Game berbasis model Think Pair and Share tidak berpengaruh terhadap hasil belajar pemahaman matematika kelas III SDN 03 Madiun Lor

TABEL 7 Analisis Uji-t Hasil Belajar Matematika

\begin{tabular}{rcccc}
\hline Varian & thitung $_{\text {nesimpulan }}$ & $\mathbf{t}_{\text {tabel }}$ & Keterangan \\
\hline $\begin{array}{l}\text { Hasil Belajar } \\
\text { Pemahaman }\end{array}$ & 20,30 & 2,101 & $t_{\text {hitung }}>t_{\text {tabel }}$ & Ha diterima \\
\hline
\end{tabular}


Berdasarkan uji hipotesis di atas dapat diketahui bahwa thitung 20,30 $>$ ttabel 2,101, sehingga Ho ditolak dan Ha diterima. Jadi dapat disimpulkan bahwa Teknik Treasure Hunt Game berbasis Model Think Pair Share berpengaruh terhadap hasil belajar Pemahaman Soal Cerita Matematika kelas III SDN 03 Madiun Lor.

Pada awal penelitian kemampuan peserta didik pada mata pelajaran matematika khususnya pada pemahaman soal cerita tergolong rendah, dibuktikan dengan hasil pretest yang telah dilakukan di awal penelitian dan banyak peserta didik yang mendapatkan nilai di bawah KKM. Dengan adanya masalah tersebut diperlukan solusi untuk mengatasi masalah tersebut. Solusi tersebut adalah dengan menerapkan strategi, metode atau teknik dalam pembelajaran yang efektif, sehingga dengan begitu dapat membantu untuk meningkatkan semangat dan kemampuan belajar peserta didik dalam memahami soal cerita. Dalam hal ini peneliti menggunakan teknik Treasure Hunt Game yang berbasis Think Pair and Share

Berdasarkan hasil olah data yang telah dilakukan bahwa Teknik Treasure Hunt Game berbasis Think Pair and Share berpengaruh terhadap pemahaman soal cerita matematika siswa kelas III SDN 03 Madiun Lor. Hal tersebut ditunjukkan dengan adanya perubahan hasil belajar dari tes pre-test dan post-test. Data yang didapatkan pada saat pretest menunjukkan 30 peserta didik mendapatkan nilai yang tidak memenuhi kritetia ketuntasan. Hal tersebut dikarenakan dalam pembelajaran guru masih menggunakan metode pembelajaran langsung yang membuat peserta didik kemungkinan merasa dan tidak memperhatikan pembelajaran. Dengan begitu peneliti menggunakan teknik Treasure Hunt Game dalam pembelajaran dan selanjutnya memberikan post-test, data yang diperoleh dari post-test kemudian diolah dan diperoleh hasil bahwa 2 peserta didik mendapatkan nilai di bawah kriteria ketuntasan.

Dengan menerapkan teknik ini tidak hanya berpengaruh terhadap hasil belajar peserta didik pada ranah kognitif, tetapi juga menimbulkan pengaruh pada keaktifan peserta didik dalam mengikuti pembelajaran. Dengan diterapkannya teknik ini, peserta didik yang awalnya tidak tertarik untuk memperhatikan proses pembelajaran menjadi aktif dan percaya diri dalam mengikuti kegiatan pembelajaran. Jadi dapat disimpulkan bahwa dengan Teknik Treasure Hunt Game berbasis Think Pair and Share berpengaruh pada pemahaman soal cerita matematika kelas III SDN 03 Madiun Lor.

\section{Kesimpulan}

Berdasarkan hasil belajar peserta didik kelas III SDN 03 Madiun Lor dalam mengerjakan soal cerita sebelum dan setelah pembelajaran dengan Teknik Treasure Hunt Game, didapatkan kenaikan dari hasil pre-test dan post-test. Dengan demikian, Teknik Tresure Hunt Game berbasis Think Pair and Game berpengaruh pada pemahaman soal cerita matematika kelas III SDN 03 Madiun Lor.

\section{DaftarPustaka}

[1] Haryono, Didi. 2014. Filsafat Matematika. Bandung: Alfabeta.

[2] Oxford Advanced Learner's Pocket Dictionary

[3] Tandilling, E. 2012. Pengembangan instrument untuk mengukur kemampuan komunikasi matematik, pemahaman matematik, dan selfregulate learning 
Pengaruh Teknik Treasure Hunt Game Berbasis Model Think Pair Share Terhadap Pengaruh Hasil Belajar Matematika Siswa Kelas III

siswa dalam pembelajaran matematika di sekolah menengah atas. Jurnal Penelitian Pendidikan, 13(1), 24-31.

[4] Amir, A. 2014. Pembelajaran Matematika SD dengan Menggunakan Media manipulatif. In FORUM PAEDAGOGIK Jurnal Pendidikan Agama Islam (Vol.6, No. 01)

[5] Sugiyono. 2015. Metode Penelitian Kuantitatif, Kualitatif, dan $R \& D$. Bandung: Alfabeta.

[6] Arikunto, Suharsimi. 2013. Prosedur Penelitian. Jakarta: Rineka Cipta. 